\title{
Editorial: The Old and the Uneducated, and the Overlooked
}

These are interesting times, politically, and philosophically too. After an unexpected and unpredicted Conservative victory in Britain in 2015 (its unexpectedness largely now forgotten), in 2016 we have witnessed an even less expected and predicted Brexit and an even more unexpected and unpredicted President-Elect Trump.

In all three cases what has been very striking was the sheer disbelief, incomprehension even, on the part of those employed by the main news organisations to foresee and comment on such matters. An immediate response from such sources was that what has been behind these seismic upheavals was the voting behaviour of the 'old and the uneducated'. This response came not just from commentators, but also from those offended by the results, in at least one case from a very great panjandrum of the EU commission, just days after the Brexit vote attempting to explain the result to his own countrymen. 'It was just the old and the uneducated', he said. And it became standard for the political elite in Europe at the same time to criticise the British government for allowing its voters a referendum in the first place.

We take no view here of the merits or demerits of the result in all or any of the three cases. What ought to strike dispassionate observers, and where there could be some agreement over and above the specific issues, is the implication of attributing a democratic decision to 'the old and the uneducated'. First of all, when we drill down into the meaning of this analysis, the old and the uneducated usually turn out to exclude not just the young and those with degrees, but also women (or at least women who understand patriarchy), ethnic minorities, the LGBT community, immigrants and many other significant groups.

In other words 'the old and the uneducated' was really code for grumpy and often old white men, no doubt a vociferous and noisy group, but hardly large enough to swing an election numerically or pleasant enough to influence anyone else. Some at least of the 'not' old and uneducated must have voted on the 'wrong' side! It seems that now there is some acknowledgement of this remarkable possibility, but among the elite the feeling still lingers that the old and the 


\section{Editorial}

uneducated really formed the core of support for the winning parties in each of our cases.

Leaving aside amusing ourselves by speculating on just who is to be included in 'the old and the uneducated', a more serious point is the clear message in these analyses that, whoever they are actually are, the old and the uneducated are not to be taken as seriously as those who voted on the other side. This is surely a denial of the fundamental democratic principle of one person, one vote, and no vote to count for more than any other. Why should an old person's vote not be as valuable as a young person's, a struggling member of the working class as valuable as a university professor's?

Apart from the fundamental inequity of apparently wanting to dismiss a vote just because it is from an uneducated and or from an old person, there is a further question about what 'educated' means here. It probably means person with a degree. But why should having a degree give one more of a voice in political decisionmaking? Karl Popper used to point out that those best able to judge the worth of political policies were those most affected by them, and there is some reason to suppose that if we were to divide a population into those with degrees and those without, those most likely to be affected adversely and most heavily are precisely those who do not have degrees, those at the bottom of the heap in terms of employment and living conditions. Openness requires respect for minorities and indeed for one's opponents (of which there has been regrettably little on all sides in recent events). But openness also requires listening to the voices of those who are too often overlooked and condemned out of hand.

Those who make the policies will tend to come from the degree possessing classes, and will certainly claim greater knowledge and expertise. In one sense they will be right, being better and more adept at policy development and analysis, but they will not be right on the crucial point of who is most affected by many of the policies governmental elites enact. Here one could be forgiven for sympathising with the British politician Michael Gove who said in the Brexit campaign that the electorate had heard quite enough from experts, and that it was time that the voice of the un-expert was listened to. As much of what we are currently seeing is the revolt of those who feel that they have been for long unheard, Gove's sentiment deserves serious consideration, rather than the near unanimous condemnation it received when he uttered it.

Finally there is the question of stereotyping and group-think. Obviously describing a view as being 'only' that of the 'old and the uneducated' is a way of dismissing it. But, as again we were counselled 
by Karl Popper, what matters is not the provenance of an opinion but its validity. Of course, the views of those who voted Conservative in Britain in 2015, for Brexit in 2016, and for President-Elect Trump might be (to coin a phrase) deplorable on all sorts of levels. That is arguable, and arguing about this could and should be as robust as can be, on both sides. Serious differences and big principles are at stake.

But those who dislike what has happened do their case no good at all by vilifying those who disagree and treating their voices with contempt. Rather the opposite: it is because the views of those who have surprisingly won in the recent democratic forums have been long overlooked that the outcome is so surprising when they do manage to make themselves heard and to exercise some influence. While we fervently hope that the winners in the recent elections will respect the rights of all, be some of those winners 'ne'er so vile', there is surely a lesson here with both political and philosophical implications. 